\title{
Did Cheaper Flights Change the Direction of Science?*
}

\author{
Christian Catalini \\ Christian Fons-Rosen \\ Patrick Gaulé \\ MIT \\ UPF, Barcelona GSE, CEPR \\ CERGE-EI, IZA
}

April 12, 2016

\begin{abstract}
We test how a reduction in travel cost affects the rate and direction of scientific research. Using a fine-grained, scientist-level dataset within chemistry (1991-2012), we find that after Southwest Airlines enters a new route, scientific collaboration increases by $50 \%$, an effect that is magnified when weighting output by quality. The benefits from the lower fares, however, are not uniform across scientist types: younger scientists and scientists that are more productive than their local peers respond the most. Thus, cheaper flights, by reducing frictions otherwise induced by geography and allowing for additional face-to-face interactions, seem to enable better matches over distance.
\end{abstract}

Keywords: scientific collaboration, air travel, temporary co-location, face-to-face meetings.

JEL Classification: 03, R4, L93

*We appreciate helpful comments from Alberto Galasso, Ina Ganguli, Avi Goldfarb, Xavier Giroud, Jeff Furman, Stepan Jurajda, Mara Lederman, Nikolas Mittag, Alex Oettl, Erin Scott, Paula Stephan, Scott Stern and seminar participants at Academy of Management, Charles University, the EPFL, Harvard Business School, Imperial College London, Stockholm School of Economics, Universidad Carlos III, and National University of Singapore for helpful discussions and advice. All errors are our own. This research contributes to the agenda Strategie AV21. Fons-Rosen acknowledges financial support by the Spanish Ministry of Economy and Competitiveness (ECO2014-55555-P). 


\section{Introduction}

Scientific collaboration has evolved substantially in recent years. Two stylized facts stand out in particular. First, the share of coauthored papers has increased over time, and high impact papers are increasingly the result of teams of authors (Jones, Wuchty \& Uzzi 2008, Wuchty, Jones \& Uzzi 2007) ${ }^{1}$. Second, distant and multi-institutional collaborations are on the rise (Adams et al. 2005, Jones, Wuchty \& Uzzi 2008).

Several explanations have been brought forward to explain these findings. Jones (2009) ties the rise in collaboration to the necessity for highly specialized scientists to build teams that cover multiple, potentially complementary sets of skills: as the body of pre-existing knowledge rapidly expands over time, no single scientist is able to master all the information required to advance the knowledge frontier on her own. In Jones' model, collaboration is a rational response to an increase in knowledge complexity.

A second explanation links the increase in co-authorship to the drastic reduction in communication costs brought by the internet: as coordination and communication costs go down, scientists are able to sustain collaboration over distance in a more efficient way. Direct empirical evidence of the effect comes from Agrawal \& Goldfarb's (2008) study of Bitnet, an internet predecessor that connected multiple universities in the U.S. in the early 80s: as more institutions joined the network, collaboration among affected scientists in the field of electrical engineering increased. Interestingly, their results hint at the technology being potentially complementary to offline interactions (e.g. face-to-face meetings), as coauthorship increases disproportionately among university pairs that are co-located. ${ }^{2}$

In this paper, we test a complementary hypothesis: that the increase in distant collaboration may also be the result of the dramatic reduction in air travel costs that took place within the United States over the last 30 years (Perry 2014), where the cost per mile dropped by over $50 \%$. To the extent that face-to-face interactions are important to establish trust, monitor effort and communicate complex ideas (Storper \& Venables 2004), cheaper flights may be instrumental in starting and sustaining collaboration over distance. ${ }^{3}$ Moreover, if offline an online interactions are complements (Gaspar \& Glaeser, 1998), then the decline in air travel costs could have amplified the documented impact of the internet.

\footnotetext{
${ }^{1}$ By 2000 , less than $20 \%$ of papers in science and engineering were single authored. Similar patterns, and in particular the rise of coauthorship and distant coauthorship, have been documented in economics. See Gaspar \& Glaeser (1998), Hamermesh \& Oster (2004), Rosenblatt \& Mobius (2004)

${ }^{2}$ Other studies have found an effect of bitnet on collaborations in the academic life sciences (Ding et al. 2010), and of the internet on R\&D cooperation within firms (Forman \& Zeebroeck 2012).

${ }^{3}$ Kim, Morse \& Zingales (2009) and Freeman, Ganguli \& Murciano-Goroff (2014) note that the secular declines in both communication costs and air travel costs may have facilitated long distance collaborations.
} 
To address endogeneity concerns, we rely on a source of variation in air travel costs that is plausibly exogenous to the scientists' research trajectories: the expansion of Southwest Airlines, a low-cost air carrier, across the United States from 1993 to 2010. Southwest has been described as the most significant development in the market structure of the U.S. airline industry by the Transportation Research Board (1999) and by industrial economists (Morrison 2001, Borenstein \& Rose 2007, Goolsbee \& Syverson 2008). The introduction of new airline routes, moreover, has been used in a different context (early-stage investment) as an instrument for the frequency of face-to-face interactions between venture capitalists and entrepreneurs (Bernstein, Giroud and Townsend, 2015).

We first document how entry by Southwest on a new route leads to, on average, a $20 \%$ drop in fares and a resulting $40 \%$ increase in passengers (with little effect on miles flown and availability of direct flights). We then exploit the differential timing of the introduction of new routes to directly estimate the impact of Southwest on scientific collaboration among U.S. cities. For this purpose we build a large sample of approximately one million ${ }^{4}$ scientific articles (1990-2009) for which we map authors' affiliations to a latitude-longitude pair, and then U.S. cities and nearby airports. We find that after Southwest entry collaborations across cities increase in chemistry (36\%), physics (26\%), engineering (49\%), and biology $(85 \%)$. This suggests that the benefits of cheaper air travel are not specific to a scientific field but may be present across the life and physical sciences.

A key concern with this first part of the analysis is that changes in local economic conditions may drive both Southwest's entry decision and the number and composition of scientists at the endpoints of the new routes. To address this issue we build a new database at the scientist-pair level for one of the fields of science in the larger sample: chemistry. This finergrained dataset enables us to use an econometric specification that includes scientist-pair fixed effects, thus holding the number and composition of scientists fixed, as well as focusing on a set of scientists - academic scientists - less likely to be immediately affected by local economic conditions. Finally, we are able to directly control for (changes in) departmental R\&D budgets which are a remaining channel through which local economic conditions could influence collaborations.

Besides helping us address identification concerns, the scientists-pair level data allows us to explore more nuanced hypotheses and questions. In particular, our analysis within chemistry focuses on changes in the rate and type of collaborations. For instance, we ask which type of scientists pairs are more affected by Southwest entry, whether the quality of

\footnotetext{
${ }^{4}$ From the full sample, 1,169,458 articles have at least one author which resolves to a U.S. address, and we are able to link $85 \%$ of them to a U.S. city.
} 
collaborations is impacted, and whether this leads to changes in the overall collaboration portfolio.

We leverage an original longitudinal dataset covering the population of faculty members in chemistry departments of research-intensive U.S. universities between 1991 and 2012. Regressing the number of copublications between pairs of scientists on Southwest entry, year fixed effects, and pair fixed effects, we find that Southwest entry leads to a large $(+50 \%)$, statistically significant increase in collaboration. The timing of the effect starts after Southwest entry (i.e., we do not observe a pre-trend in collaboration), and our coefficient of interest is unaffected when we control for time-varying departmental research budgets. The absence of a pre-trend in collaboration reassures us of the exogeneity of Southwest entry to the individual scientific trajectories involved.

We then use our empirical setting to explore how Southwest changes scientific collaboration. First, we consider whether the additional publications induced by Southwest are of high versus low quality by weighting them by the number of citations they receive: results are stronger for citation-weighted publications, which suggests that the work enabled by the cheaper fares was not of marginal quality. Next, we explore whether Southwest had a stronger effect for established versus new collaborators. Whereas the effect is present both on the intensive and the extensive margin, the intensive margin is twice as large, suggesting that established co-authors benefited the most from the introduction of the cheaper fares. To shed further light on potential mechanisms, we test if scientists rebalance their collaboration portfolios away from distant scientists on routes not affected by the cheaper fares and in favor of co-authors affected by Southwest. While we do not find direct evidence of crowding out when looking at raw copublications numbers, when we weight papers by citations to account for quality, the resulting collaborations increase at a substantially lower rate than those affected by Southwest.

Finally, we explore heterogeneous effects by scientists type, and discover that Southwest entry had a stronger effect among younger scientists, scientists that are more productive than their department average, and scientists that are specialized in different areas (higher distance in scientific space).

Besides highlighting the role of collaboration costs in shaping scientists' co-authorship decisions, our paper contributes to the growing literature on the role of geography on scientific knowledge production. Early studies (Katz 1994, Mairesse \& Turner 2005) found that proximity among labs strongly correlates with the incidence of scientific collaboration. More recently, Catalini (2015) identifies the causal effect of proximity on the rate and direction of scientific collaboration using the natural experiment arising from the reshuffling of labs on 
the Jussieu campus of Paris following the removal of asbestos from its buildings. Besides permanent co-location, temporary co-location may also remove frictions to scientific collaboration: in a field experiment at Harvard University, Boudreau et al. (2014) find that being in the same room during a scientific symposium leads to a large increase in the propensity that any two scientists will co-apply for a grant. Similarly, Chai (2014) shows that participation in the same conference is positively correlated with future collaboration. Our findings suggest that travel costs also have a tangible effect on the rate and trajectory of science, potentially because of the way they influence the likelihood that any two scientists will spend time interacting face-to-face.

The rest of the paper is as follows: in Section 2, we describe the data sources used in the paper as well as the data construction process. In Section 3 we introduce the empirical strategy. In Section 4 we present our main effect and heterogeneous effects in terms of extensive and intensive margin and scientist characteristics. Section 5 concludes.

\section{Data}

\subsection{Data Sources and Construction}

To examine the effect of air travel costs on scientific collaboration, we combine data on scientists with publication records and air transportation information. While we initially show our main result within a large sample of scientific articles in biology, chemistry, physics and engineering, we focus most of our analysis on our more detailed chemistry dataset. Within the chemistry sample, biographical information on scientists enables us to effectively disambiguate publication data, while also allowing us to separate faculty members from other types of authors.

Air Transportation Data - To recover information on when Southwest operated flights between different routes, as well as information on prices, passengers and miles flown, we use data from the Airline Origin and Destination Survey (DB1B) of the U.S. Bureau of Transportation Statistics. Reporting is mandatory for airlines and the data is a $10 \%$ sample of U.S. domestic itineraries, tracking passengers across flight changes. This data is available only from 1993, hence we will focus on Southwest entry decisions that occur after 1993.

Match Between Airports and Universities. We compute distances between airports and universities using Google Maps. The matching between universities and airports is com-

plicated by the fact that the same metropolitan area could be served by multiple airports 
(e.g. O'Hare and Midway in Chicago) or that a college town could be half-way between two airports. We chose to match universities to all airports within a 50 miles radius. ${ }^{5}$ We code the year of Southwest entry for a pair of universities as the first year in which Southwest operates a flight on any route whose endpoints (airports) are within 50 miles of the respective universities.

\subsection{Large Sample of Publications in Biology, Chemistry, Physics and Engineering}

The larger sample of co-publications allows us to compare the effect of Southwest across different disciplines. Since we do not have information on faculty members outside of chemistry, this dataset is based on geocoded publications and structured at the city-pair level. The starting point for the construction of this sample is the population of scientific articles published in 477 leading scientific journals in biology, chemistry, physics and engineering between 1990 and 2009. ${ }^{6}$ We have a total of 2,773,560 papers published between 1990 and 2009, of which 1,169,458 had at least one author with a U.S. address. Out of all papers with U.S. addresses, we were able to successfully map 994,672 (85\%) to a U.S. CBSA ${ }^{7}$ using a combination of three different geocoding services (Google Maps API, Bing Maps API, and the Data Science Toolkit). This allows us to link the vast majority of U.S. papers to the geographic regions involved in their production.

\footnotetext{
${ }^{5}$ Some universities do not have any airports in a 50 miles radius, and scientists located in those universities are excluded from the analysis. Results are robust to assigning them to the nearest airport.

${ }^{6}$ These journals include large multidisciplinary journals such as Science, Nature, Proceedings of the National Academy of Sciences. The leading journals in biology, chemistry, physics and engineering are included, but the coverage is skewed towards biology and chemistry with these disciplines representing a greater share of the total number of journals.

7 "CBSA is a collective term for both metro and micro areas. A metro area contains a core urban area population of 50,000 or more and a micro area contains an urban core population of at least 10,000 (but less than $50,000)$. Each metro or micro area consists of one or more counties and includes the counties containing the core urban area, as well as any adjacent counties that have a high degree of social and economic integration (as measured by commuting to work) with the urban core." Source: http://www.census.gov/population/metro/. The full list of CBSAs is available at: http://www.census.gov/population/metro/data/def.html. The 994,672 papers with US authors had a total of $3,668,971$ US affiliations on them.
} 


\subsection{Chemistry Dataset}

\subsubsection{Data on Scientists}

Our focus is on collaborations across faculty members (and therefore effectively across labs ${ }^{8}$ ) in the discipline of chemistry $^{9}$, in part due to data availability, and in part because of the short publications cycles in this discipline. For biographical information on scientists, our data source is the directory of graduate research published by the American Chemical Society. Intended as a source of information for prospective graduate students, this directory provides comprehensive listings of faculty affiliated with U.S. departments granting PhDs in chemistry, chemical engineering and biochemistry. Besides faculty names and departmental affiliations, the directory provides information on year of birth, gender and education. The directory is published biannually in print and, since 1999, on the web. ${ }^{10}$ We combine the directories from 1991 to 2013 to build a longitudinal panel of over 20,000 scientists. We complement this information with department-level R\&D expenditures from The National Science Foundation (NSF) Survey of Research and Development Expenditures at Universities and Colleges.

\subsubsection{Publication Data}

We match faculty names to publication data from Scopus covering more than 200 chemistry journals, multidisciplinary journals and major journals in neighboring disciplines. ${ }^{11}$ Within chemistry, the match between publications and scientists is facilitated by the fact that we know institutional affiliations from faculty data. We match publications to faculty based on last name, first and (if non-missing) middle initials, departmental and university affiliation. From publication data, we construct for each scientist time-varying measures of past productivity (with a moving average over the last three years of publication counts weighted by journal impact factor). We also infer our main outcome, copublications, from bibliometric

\footnotetext{
${ }^{8}$ In the hard and life sciences, an important share of authors on papers are graduate students, postdocs and technicians. These are typically employed in the lab of a faculty member who obtains funding for the lab, appears as a coauthor on lab publications, oversees resource allocation within the lab and effectively decides whether to collaborate with other (possibly geographically distant) labs.

${ }^{9}$ Chemistry, which focuses on the composition, structure, transformations and properties of matter, is a large discipline, with chemistry $\mathrm{PhD}$ graduates accounting for $30 \%$ of U.S. PhD science graduates.

${ }^{10}$ The American Chemical Society also produced a CD-ROM for the years 1991-1993.

${ }^{11}$ Scopus is one of the two major bibliometric databases (along with ISI Web of Science). Our set of chemistry journals includes all journals from the American Chemical Society, as well as any chemistry journal with impact factor above 2. Our set of multidisciplinary journals includes Nature, Science, Cell and the Proceedings of the National Academy of Sciences. Our set of major journals in neighboring disciplines includes all journals with impact factor above 6 in physics, biology, material science and nanotechnology.
} 
data. The majority (75\%) of papers matched to a faculty member have exactly one faculty author, $21 \%$ percent have two, and less than $4 \%$ have more than two authors. ${ }^{12}$ A paper with more than 2 faculty authors is counted as a copublication between all pairs of faculty members involved.

\subsubsection{Sample Selection and Descriptive Statistics}

Our chemistry dataset covers over 20,000 scientists and their collaborations. However, we focus on a specific subset of pairs of scientists who experience Southwest entry and for whom we have variation in collaboration over time. Since all regressions include scientist-pair fixed effects, pairs that never collaborate drop out of the sample. We have 15,244 pairs of scientists who collaborate at least once. ${ }^{13}$ Excluding co-authors that are in the same department, we have 8,311 pairs of scientists. Only a minority $(1,158)$ of those pairs experience Southwest entry during our analysis period of 1993-2012, either because for the other 7,000 Southwest is already operating a flight or because Southwest never flies between the relevant endpoints. We drop pairs in locations where Southwest enters but then leaves within two years, as well as pairs where Southwest entry coincides with the move of a scientist. ${ }^{14}$. Our final analysis covers 819 pairs of scientists corresponding to 890 individuals.

[Insert table 1 about here]

Table 1 displays descriptive statistics for our chemistry sample at different levels of analysis: individual, individual-pair and individual-pair-year. Most individuals in the sample are male $(90 \%)$ with an average age at time of Southwest entry of 49.7. We do not observe individual research budgets but as a rough proxy we use departmental R\&D expenses divided by the number of faculty members in the department. The median faculty member in our sample is in a department where departmental $R \& D$ expenses divided by the number of faculty members is $\$ 212,000$ at the time of Southwest entry. According to the NSF Survey, R\&D expenses include compensation for R\&D personnel, equipment and indirect costs. In terms

\footnotetext{
${ }^{12}$ Both papers with one faculty author and papers with multiple faculty authors would typically have several non-faculty authors. We focus on faculty authors for reasons mentioned earlier in text. We also find papers in chemistry journals that are not matched to any of our U.S. faculty authors: these are probably foreign scientists, or scientists working in corporate environments or federal labs.

${ }^{13}$ Our dyadic data is not directed, and thus is symmetric: the pair between $i$ and $j$ is the mirror image of the pair between $j$ and $i$. The 15,244 figure is after dropping 15,244 symmetric observations.

${ }^{14}$ Scientists in our sample may move from one department to another, in some cases leading to a change in whether they are connected by Southwest or not. We want changes in Southwest status to be driven by Southwest entry decisions rather than by location decisions, and thus exclude pairs who happen to move in the same year as Southwest enters, the year before Southwest entry or the year after Southwest entry.
} 
of specialization ${ }^{15}$, the largest area is physical chemistry $(32 \%)$, followed by biochemistry $(23 \%)$, inorganic chemistry $(13 \%)$, organic chemistry $(14 \%)$ and material science $(11 \%)$.

We observe our 819 pairs for 17 years on average ${ }^{16}$ for 14,187 observations at the individualpair-year level. Southwest entry corresponds to 413 distinct new routes. The median pair experiences Southwest entry in 1999 but we observe Southwest entry from 1994 to 2011. The mean number of copublications over the whole period is 1.9 but the majority of pairs copublishes only once; only $9 \%$ of pairs collaborates both before and after Southwest entry.

\section{Empirical Strategy}

Our econometric specification is a straightforward difference-in-differences framework at the scientist-pair level. We focus on a Poisson model with dyadic fixed effects, but show robustness to additional specifications in the Appendix. Our approach exploits variation in Southwest entry across different airport pairs over time:

$$
Y_{i j t}=\beta \text { After } S W_{i j t}+\mu_{t}+\gamma_{i j}+\epsilon_{i j t}
$$

where $Y_{i j t}$ is the number of co-publications between scientist $i$ and scientist $j$ in year $t$, After $S W_{i j t}$ is an indicator variable that takes value 1 after Southwest entry, $\mu_{t}$ is a year fixed effect, $\gamma_{i j}$ is a pair fixed effect to control for underlying time-invariant differences across pairs of scientists, and $\epsilon_{i j t}$ is an idiosyncratic error term.

Our analysis examines the change in collaboration over time for pairs that co-publish at least one paper during our sample period. The pair fixed effects completely capture dyads of scientists for which we never see activity, and thus we remove these pairs from the analysis without empirical consequence. Robust standard errors are clustered at the pair level.

\footnotetext{
${ }^{15}$ Specialization is inferred based upon the journals in which a scientists publishes. For instance, a faculty member who often publishes in the Journal of Biological Chemistry is assumed to to be specialized in biochemistry. Appendix table A3 displays a listing of areas of specialization and an example journal for each one of them.

${ }^{16}$ A pair is in our sample for a maximum of 22 years (from 1991 to 2011). We observe some pairs for less than 22 years due to pair members starting their first faculty appointment after 1991, retiring before 2011, or otherwise no longer being listed in the ACS faculty directory.
} 


\section{Results}

We build our results in three steps: 1) we document the effect Southwest entry had on the air travel market by providing descriptive information on its impact on the number of passengers, prices, miles flown, and transfers; 2) we present data on how Southwest influenced collaborations in biology, chemistry, physics and engineering; 3) we turn to our main result and heterogeneous effects based on the econometric specification just introduced within the fine-grained chemistry sample.

The larger dataset allows us to show that the airline's entry had a broad and generally comparable impact across a very diverse set of research environments. Since we do not have access to information on individual faculty members outside of chemistry, we run this part of the analysis at the U.S. CBSA-pair-year level, thereby including all collaborations between scientists within each pair of regions.

The chemistry dataset provides us instead with the precision required to further test our identification strategy: one concern with the city-pair regressions is that Southwest may be more likely to enter pairs of cities that are growing. Growing cities may also attract an increasing number of researchers over time, and their publications may grow as a result of this overall trend. Moving to the scientist pair level, we can hold the sample of researchers constant and specifically focus on changes occurring within pairs of individuals, thus mitigating this concern. The chemistry dataset also allows us to control for R\&D budgets, to exploit heterogeneity by scientists type and observe changes in the overall portfolio of projects a scientist is working on.

\subsection{Southwest Entry and Passengers, Prices, Miles and Transfers}

In Table 2 we look at how Southwest entry is correlated with some of the key passenger and fare metrics of interests in the air travel industry. The coefficients reflect the types of changes one would expect to take place after the entry of a low-cost competitor: the number of passengers increases by approximately $44 \%$, and prices drop by around $20 \%$, both results being strongly statistically significant. We do not find any effect on miles flown or direct flights, and the reduction in the number of transfers is of very small magnitude. Overall, these results are consistent with the idea that Southwest lowers the cost of air travel without providing many new additional direct routes.

[Insert table 2 about here] 


\subsection{Aggregate Changes in the Rate of Collaboration Across US Regions}

To test if the availability of cheaper flights had an effect on scientific collaboration across fields, we use a large-scale publication dataset covering close to a million papers matched to a U.S. CBSAs. Specifically, we explore how collaboration between any two CBSAs changed after Southwest starts operating a new route between them. The unit of analysis is the CBSA-pair-year (48,274 pairs), and we include pair and year fixed effects to respectively control for underlying differences across regions that are consistent over time, and overall time trend. For the estimation, we use a Poisson model with standard errors clustered at the CBSA-pair level.

[Insert table 3 about here]

Results are displayed in Table 3. In column (1) we find that Southwest entry is associated with a $77 \%$ increase in collaborations in the full sample, with comparable effects across the different fields of science (columns (2)-(5)).

A key issue with this specification is that we cannot control for scientists' characteristics and departmental funding, as we do not have access to a faculty directory list outside of chemistry. Micropolitan and metropolitan areas may also be too large as a unit of analysis for correctly measuring the effects of interest. For the rest of the analysis we therefore focus on chemistry papers and scientists, and we shift from regional pairs to scientist pairs. This allows us to introduce scientist-pair fixed effects and account for idiosyncratic, unobservable, and time invariant reasons that may drive collaboration between any two scientists.

Since chemistry, according to the estimates in Table 3, is not an outlier in either direction (if anything, the effects within the field are in the lower end of the spectrum), we believe the results from the following sections are potentially generalizable to other fields.

\subsection{Changes in Collaboration Within Chemistry}

Cheaper flights make collaborating over distance less costly and potentially more efficient (e.g. because of the ability to meet face-to-face), and should therefore lead to an increase in the rate of collaboration among scientist-pairs who are now connected through Southwest. Column (1) in Table 4 runs the main econometric specification previously described and shows a large and statistically significant effect, with scientist-pairs increasing their pairwise 
collaborations by approximately 50\%. ${ }^{17}$ In the Appendix, we explore if our main effect varies across fields of chemistry, and find very similar results for physical chemistry, biochemistry, inorganic chemistry, material science and organic chemistry.

\subsubsection{Endogeneity of Southwest Entry}

One may worry that Southwest entry is systematically correlated with growth within the universities involved at both ends of the routes, i.e., that collaboration would have increased even in the absence of cheaper flights. While we cannot directly address the simultaneity issue, in columns (2) and (3) we address the key endogeneity concerns by ruling out alternative explanations.

\section{[Insert table 4 about here]}

In column (2) we control for the (log of) departmental R\&D budget per faculty member to account for variation in growth prospects across departments or regions. While the coefficient is positive and statistically significant, our main result is unaffected. In column (3) we follow Bernstein, Giroud, and Townsend (2015) and study the dynamic effects of the introduction of new airline routes. Specifically, we replace the treatment indicator Southwest entry in column (1) with a set of four indicator variables representing the years around the treatment. For example, the indicator 'Southwest entry $(-1)$ ' equals one if the scientist pair observation is recorded one year prior to the treatment. The other indicator variables are defined analogously with respect to the year of the treatment (0), the first year after the treatment (1), and two or more years after the treatment $(2+)$. We find that the coefficient of 'Southwest entry $(-1)^{\prime}$ ', which measures the 'effect' of the new airline routes before their introduction, is small and insignificant, suggesting that there are no pre-existing trends in the data. It is only once Southwest opens the route that the coefficients turn positive and statistically significant.

In an additional test of our identification strategy, Figure 1 explores the presence of a pre-trend in the data by plotting the regression coefficient estimates for the 5 years before and 5 years after Southwest entry. We again see no pre-trend before Southwest launches the route. It is only after the new route is available that the estimated yearly coefficients are positive and steadily increasing in their magnitude.

\footnotetext{
${ }^{17}$ Other studies find comparable effects when looking at the impact of communication costs and search cost on collaboration: for instance, Agrawal \& Goldfarb (2008) find that Bitnet increased the likelihood of collaboration between pairs of universities by 40\%; Boudreau et al. (2014) find that a 90-minute structured information sharing session leads to a $75 \%$ higher probability of co-applying for a grant.
} 
Overall, we believe results in Table 4 and Figure 1 provide robustness to our interpretation of the main effect, and reassure us that we are not simply measuring some underlying, unobservable process that takes place with each entry (as we observe Southwest arrival across multiple locations and years), and drives both Southwest decisions and the increase in scientific collaboration.

\subsubsection{Quality Effects, Portfolio Adjustments and Intensive versus Extensive Margin}

Until this point we have documented a tangible increase in the number of collaborations between scientists following the introduction of a cheaper route between them. On the one hand, one may worry that these are just marginal collaborations, and therefore less valuable from a scientific viewpoint. On the other hand, if face-to-face meetings substantially improve knowledge production (e.g., because of better monitoring, communication of complex ideas, coordination etc.), then we would expect these additional collaborations to be of higher average quality. Moreover, if cheaper access to temporary co-location is important enough to shift the choice between alternative, distant research projects, scientists may adjust their collaboration portfolio in response to lower prices.

[Insert table 5 about here]

In Table 5, we weight our dependent variable, copublications, by citations received (a proxy for scientific impact and quality): whereas our main effect translated into a $50 \%$ increase in collaborations when every scientific paper is considered the same, the increase is closer to $80 \%$ when output is weighted by citations. This is inconsistent with the additional collaborations being lower quality ones, and supports the idea that scientists may be able to do higher quality work, select better collaboration opportunities, or potentially both when travel costs are reduced.

In column (3), we explore if the cheaper fares crowd out collaborations with distant coauthors not affected by Southwest entry. While we do not find a decline in collaboration (distant copublications increase by approximately 11\%), we do not observe a disproportionate increase in collaboration when we weight papers by citations (column (4)), similar to the one we found in columns (1) and (2). It is important to stress that we only observe research projects that ultimately end up in a publication, so crowding out could still be taking place, but we may not be able to fully capture it.

[Insert table 6 about here] 
In Table 6 we decompose the effect between pairs of scientists who collaborate both before and after Southwest entry (intensive margin pairs) versus pairs of scientists who collaborate either before or after entry, but not both (extensive margin pairs). We find a stronger effect for intensive margin pairs (column (2)), consistent with the idea that even a few, additional face-to-face meetings could have a tangible impact on the rate of scientific collaboration. Interestingly, cheaper fares also seem to enable experimentation in the form of new collaborations over distance (column (3)).

The evidence from the full sample suggests that cheaper fares not only facilitated more collaborations over distance, but also higher quality ones. While we observe an increase in terms of copublications counts on both margins, larger effects on the intensive margin are consistent with established pairs being more responsive to the availability of cheaper flights. This is consistent with selection, as scientists that have already collaborated may incur lower costs when adding a new project with the same distant scientist. On the intensive margin, moreover, air travel costs may represent a larger relative share of the total, incremental costs of an additional collaboration. Established co-author pairs may also become more efficient at using temporary co-location to push projects forward or may derive higher consumption utility from spending time together. This generates conflicting predictions in terms of output quality, as in the first case (efficiency story) we would expect intensive margin collaborations to generate higher quality work when the cheaper fares become available, whereas in the second case (consumption utility story) we would observe the exact opposite.

Columns (5) and (6), while not conclusive, are suggestive of extensive margin pairs (column (6)) producing higher quality collaborations after Southwest entry. The coefficient in column (5) is smaller and not significant, which may mean that both the efficiency and the consumption utility story are present within the same sample, or that we simply we do not have enough observations to estimate the effect precisely. The higher coefficient in column (6) is also consistent with selection, i.e. conditional on starting a new collaboration over distance, given that setup costs may be higher, we would expect outputs to be of higher average quality.

\subsubsection{Heterogeneous Effects as a Function of Scientist Characteristics}

Taken together, results in Table 6 hint at potential arbitrage opportunities opened up by the lower fares: scientists may be able to find better matches over distance when travel costs drop, i.e. when the frictions introduced by geographic distance are reduced.

[Insert table 7 about here] 
In Table 7 we directly test what types of scientists are more likely to benefit from this reduction in costs due to geographic distance. Not surprisingly, younger scientists, who may have more difficulty accessing funding, are more responsive to the cheaper fares (column (1)). While the main coefficient is still statistically significant on its own (albeit with a lower estimated value), the interaction term that includes the subset of pairs where both are less than 50 years of age is three times larger than the main effect. This is consistent with our interpretation that the fares had a causal effect on the rate of scientific collaboration.

Furthermore, in column (2) we observe that the effect is entirely driven by pairs where at least one of the two individuals is more productive than the local departmental peers, and is particularly strong when both scientists are more productive than their peers. Cheaper fares seem to help individuals that are talented, but potentially do not have access to co-authors of comparable quality within their local environment. They might be in peripheral institutions because of mismatches in the labor market for scientific talent within chemistry, or because of their geographic preferences. As travel cost drop and geography becomes less important (potentially also because of the complementary role of the internet) these individuals are able to find and sustain better matches over distance.

Another dimension along which arbitrage opportunities may arise as travel costs drop is across different areas of expertise. In column (3), we test whether the effect of Southwest entry was stronger for scientists more distant in knowledge space, as proxied by publishing in different subfields of chemistry. Collaborations between different subdisciplines may also benefit disproportionally from face-to-face meetings because of a greater need to exchange complex information that is less familiar to at least one of the collaborators, or these pairs may be simply collaborating to access specialized equipment or expertise not available locally. We find a stronger effect of Southwest entry for collaborations that are distant in scientific space, which again is consistent with lower travel costs opening up different types of collaboration opportunities.

In columns (4) and (5) we respectively interact the Southwest entry dummy with departments below median R\&D budgets and at different levels of distance: while the coefficients are positive and in the expected direction, results are fairly noisy and not significant. At least, the results point in the direction that scientists with more severe budget constraints or that are more distant (where travel costs are likely to play a larger role) benefit more from Southwest.

The last column of Table 7, which includes all our interactions, summarizes the key findings of this section: Southwest entry is associated with an increase in collaboration among younger, more productive scientists, potentially at the cost of collaborations between 
scientists that do not fit this pattern (the baseline in column (6) is negative and significant). Cheaper fares, by lowering the cost of collaboration over distance (and allowing for additional face-to-face meetings) have a tangible effect on the rate and direction of scientific research within chemistry.

\section{Conclusion}

In this paper, we investigated the effects of a reduction in air travel costs on the rate and direction of scientific research. We rely on the differential timing of entry of a low-cost carrier (Southwest Airlines) across multiple U.S. locations to estimate if and how a reduction in air fares influences scientific collaboration.

Our difference-in-differences empirical strategy, combined with our robustness tests, supports the idea that the availability of cheaper fares has a causal effect on the rate at which scientists collaborate. The effect is present across multiple fields of science (chemistry, physics, biology and engineering), and is robust to controlling for idiosyncratic scientist-pair characteristics, trends in collaboration over time, and department R\&D budgets. Moreover, consistent with a causal interpretation, we do not observe a pre-trend in collaboration between scientist pairs that are going to experience Southwest entry in the future.

Using a fine-grained, scientist-level dataset covering all U.S. chemistry faculty members (1991-2013), we show that the entry of a low-cost carrier did not induce marginal, lowerquality collaborations: when we weight scientific output by citations, our estimates suggest an $80 \%$ increase in quality-adjusted publications. Interestingly, whereas the increase in raw output predominantly comes from established co-author pairs (intensive margin), the quality result seems to be stronger for scientist pairs deciding to collaborate for the first time (extensive margin). This is consistent with existing collaborators incurring lower costs when adding additional projects (e.g., because of learning effects, efficiency improvements over time or simply because of higher consumption utility), but also with the cheaper fares enabling collaborations between scientists that would have not worked together otherwise.

Our results support the idea that as frictions due to geographic distance are reduced, scientists are able to adjust their collaboration portfolios accordingly, potentially finding better matches over distance. Whereas in Agrawal \& Goldfarb (2008)'s paper the democratization in the production of new scientific knowledge is the result of a reduction in communication costs (the introduction of Bitnet, an internet predecessor), in our paper similar effects arise from a drop in travel costs. 
Cheaper air travel, by counterbalancing how geographic distance constrains collaboration choices at stages when face-to-face interactions cannot be substituted for remote interactions, may have a significant effect on the generation and recombination of scientific knowledge. Our results point to younger scientists, scientists that have less access to funding, and scientists that are more productive than their local peers as the main beneficiaries of the reduction in travel costs. Given that the savings involved are relatively modest relatively to the overall cost of a research project in the fields we studied, a potential policy implication of our results would be to support scientists with limited budgets through travel grants. 


\section{References}

Adams, J. D., Black, G. C., Clemmons, J. R., \& Stephan, P. E. (2005). Scientific teams and institutional collaborations: Evidence from US universities, 19811999. Research policy, 34(3), 259-285.

Agrawal, A., \& Goldfarb, A. (2008). Restructuring Research: Communication Costs and the Democratization of University Innovation. American Economic Review, 98(4), 1578-90.

Bernstein, S., Giroud, X., \& Townsend, R. R. (2015). The Impact of Venture Capital Monitoring. The Journal of Finance.

Borenstein, S., \& Rose, N. L. (2007). How airline markets work... or do they? Regulatory reform in the airline industry. No. w13452. National Bureau of Economic Research.

Boudreau, K. J., Brady, T., Ganguli, I., Gaule, P., Guinan, E., Hollenberg, T., \& Lakhani, K. (2014). A field experiment on search costs and the formation of scientific collaborations. Available at SSRN 2486068.

Catalini, C. (2015). Microgeography and the direction of inventive activity. Rotman School of Management Working Paper, (2126890).

Ding, W. W., Levin, S. G., Stephan, P. E., \& Winkler, A. E. (2010). The impact of information technology on academic scientists' productivity and collaboration patterns. Management Science, 56(9), 1439-1461.

Forman, C., \& Zeebroeck, N. V. (2012). From wires to partners: How the Internet has fostered R\&D collaborations within firms. Management science, 58(8), 1549-1568.

Freeman, R. B., Ganguli, I., \& Murciano-Goroff, R. (2014). Why and wherefore of increased scientific collaboration (No. w19819). National Bureau of Economic Research.

Gaspar, J., \& Glaeser, E. L. (1998). Information technology and the future of cities. Journal of Urban Economics, 43(1), 136-156.

Goolsbee, A., \& Syverson, C. (2008). How Do Incumbents Respond to the Threat of Entry? Evidence from the Major Airlines. The Quarterly Journal of Economics, 123(4), 1611-1633.

Hamermesh, D., \& Oster, S. (2002) "Tools or Toys? The Impact of High Technology on Scholarly Productivity" Economic Inquiry 40(4):539-555

Jones, B. F. (2009). The burden of knowledge and the death of the renaissance man: Is innovation getting harder? The Review of Economic Studies, 76(1), 283-317. 
Jones, B.F., Wuchty, S., Uzzi, B. (2008). Multi-University Research Teams: Shifting Impact, Geography and Stratification in Science. Science 322(5905), 1259-1262

Katz, J. (1994). Geographical proximity and scientific collaboration. Scientometrics, $31(1), 31-43$.

Kim, E. H., Morse, A., \& Zingales, L. (2009). Are elite universities losing their competitive edge? Journal of Financial Economics, 93(3), 353-381.

Mairesse, J., \& Turner, L. (2005). Measurement and explanation of the intensity of copublication in scientific research: An analysis at the laboratory level. NBER Working Paper No 11172. National Bureau of Economic Research.

Morrison, S. A. (2001). Actual, adjacent, and potential competition: Estimating the full effect of Southwest Airlines. Journal of Transport Economics and Policy, 239-256.

Perry, M. (2014) "The cost of air travel in the US has been remarkably stable for the last decade, and $17 \%$ cheaper than 20 years ago" Carpe Diem, Blog of American Entreprise Institute. https://www.aei.org/publication/the-cost-of-air-travel-in-the-us-hasbeen-remarkably-stable-for-the-last-decade-and-17-cheaper-than-20-years-ago/ accessed March 17,2016

Rosenblatt T. \& Mobius M. (2004) Getting closer or drifting apart? Quarterly Journal of Economics 119(3):971-1009

Stephan, P. E. (2012). How Economics Shapes Science. Cambridge, MA: Harvard University Press.

Storper, M., \& Venables, A. J. (2004). Buzz: face-to-face contact and the urban economy. Journal of Economic Geography, 4(4), 351-370.

Transportation Research Board, National Research Council (1999): Entry and Competition in the US Airline Industry: Issues and Opportunities. Washington, DC: National Academy Press

Wuchty, S., Jones, B. F., \& Uzzi, B. (2007). The increasing dominance of teams in production of knowledge. Science, 316(5827), 1036-1039. 


\section{Tables and Figures}

Table 1: Summary statistics

\begin{tabular}{lcccccccc}
\hline \multicolumn{1}{c}{ Variable } & Obs & Mean & Std. Dev. & Min & Max & P25 & P50 & P75 \\
\hline Individual scientist level & & & & & & & & \\
Age & 890 & 49.7 & 11.2 & 27 & 85 & 41 & 49 & 58 \\
Female & 890 & .10 & .30 & 0 & 1 & 0 & 0 & 0 \\
Average R\&D budget & 890 & 285.32 & 258.33 & .55 & 2944 & 122.63 & 212.85 & 370.70 \\
in dept. (1000s USD) & & & & & & & & \\
Speciality: & & & & & & & & \\
$\quad$ Physical chemistry & 890 & .32 & .47 & 0 & 1 & 0 & 0 & 1 \\
$\quad$ Biochemistry & 890 & .23 & .42 & 0 & 1 & 0 & 0 & 0 \\
$\quad$ Inorganic chemistry & 890 & .13 & .34 & 0 & 1 & 0 & 0 & 0 \\
$\quad$ Organic chemistry & 890 & .14 & .34 & 0 & 1 & 0 & 0 & 0 \\
$\quad$ Material science & 890 & .11 & .31 & 0 & 1 & 0 & 0 & 0 \\
$\quad$ Other & 890 & .08 & .26 & 0 & 1 & 0 & 0 & 0 \\
& & & & & & & & \\
Individual-pair level & & & & & & & & \\
Year of SW entry & 819 & 2001 & 4.3 & 1994 & 2011 & 1999 & 1999 & 2005 \\
Distance (in miles) & 819 & 1151 & 829.9 & 49 & 5086 & 443.5 & 878.1 & 1806.6 \\
Years in sample & 819 & 17 & 4.6 & 4 & 22 & 14 & 18 & 22 \\
Total copublications & 819 & 1.9 & 3.3 & 1 & 65 & 1 & 1 & 2 \\
Copub. both before and after & 819 & .09 & .28 & 0 & 1 & 0 & 0 & 0 \\
In different field of chemistry & 819 & .45 & .5 & 0 & 1 & 0 & 0 & 1 \\
Individual-pair-year level & & & & & & & & \\
Copublications & 14187 & .11 & .41 & 0 & 13 & 0 & 0 & 0 \\
Cites-weighted copublications & 14187 & 4.1 & 27.8 & 0 & 1487 & 0 & 0 & 0 \\
Dummy for any copublication & 14187 & .08 & .28 & 0 & 1 & 0 & 0 & 0 \\
\hline
\end{tabular}


Table 2: Effects of Southwest entry on price, passengers and routes

\begin{tabular}{|c|c|c|c|c|c|}
\hline & $\begin{array}{c}(1) \\
\text { Passengers } \\
(\log )\end{array}$ & $\begin{array}{l}(2) \\
\text { Mean price } \\
(\log )\end{array}$ & $\begin{array}{c}(3) \\
\text { Miles flown } \\
(\log )\end{array}$ & $\begin{array}{c}(4) \\
\text { Direct flight }\end{array}$ & $\begin{array}{c}(5) \\
\text { Nr transfers }\end{array}$ \\
\hline Southwest entry & $\begin{array}{c}0.4437^{* * * *} \\
(0.0050)\end{array}$ & $\begin{array}{c}-0.1910 * * * \\
(0.0024)\end{array}$ & $\begin{array}{c}0.0007 \\
(0.0006)\end{array}$ & $\begin{array}{c}0.0002 \\
(0.0004)\end{array}$ & $\begin{array}{c}-0.0174^{* * *} \\
(0.0017)\end{array}$ \\
\hline Pair Fixed Effects & Yes & Yes & Yes & Yes & Yes \\
\hline Year Fixed Effects & Yes & Yes & Yes & Yes & Yes \\
\hline Mean of dep. variable & 4.238 & 5.454 & 7.066 & 0.007 & 1.239 \\
\hline Number of pairs & 55750 & 55750 & 55739 & 55750 & 55750 \\
\hline Number of observations & 956029 & 956029 & 955983 & 956029 & 956029 \\
\hline
\end{tabular}

Notes: Robust standard errors in parentheses ${ }^{*} p<0.1,{ }^{* *} p<0.05,{ }^{* * *} p<0.01$. Southwest entry is an indicator variable that takes value 1 if Southwest has started operating a flight between airports. All specifications include airport-pair fixed effects and year fixed effects. Estimation by ordinary least squares.

Table 3: Southwest entry and collaborations between US cities (CBSAs)

\begin{tabular}{lccccc}
\hline & $(1)$ & $(2)$ & $(3)$ & $(4)$ & $(5)$ \\
& All copubs & Chemistry & Biology & Physics & Engineering \\
\hline Southwest entry & $0.775^{* * *}$ & $0.365^{* * *}$ & $0.859^{* * *}$ & $0.257^{* * *}$ & $0.493^{* * *}$ \\
& $(0.027)$ & $(0.035)$ & $(0.039)$ & $(0.033)$ & $(0.063)$ \\
\hline Pair Fixed Effects & Yes & Yes & Yes & Yes & Yes \\
Year Fixed Effects & Yes & Yes & Yes & Yes & Yes \\
Number of pairs & 48274 & 15303 & 22079 & 15872 & 7635 \\
Number of observations & 965480 & 306060 & 441580 & 317440 & 152700 \\
\hline
\end{tabular}

Notes: Robust standard errors in parentheses ${ }^{*} p<0.1,{ }^{* *} p<0.05,{ }^{* * *} p<0.01$. These regressions are run at the city (CBSA) -pair level. The dependent variable is the number of copublications between pairs of cities. Southwest entry is an indicator variable that takes value 1 if Southwest has started operating a flight from airports close to the respective cities. Column 1 is based on copublications in all journals in our sample. Columns 2, 3, 4, 5, are based on chemistry, biology, physics and engineering journals respectively. All specifications include city-pair fixed effects and year fixed effects. Estimation by Poisson Quasi-Maximum Likelihood. 
Table 4: Effect of Southwest entry on co-publications at the individual-pair level

\begin{tabular}{lcc}
\hline DV $=$ Co-publications & $(1)$ & $(2)$ \\
\hline Southwest entry & $0.482^{* * *}$ & $0.493^{* * *}$ \\
& $(0.118)$ & $(0.117)$ \\
Dept R\&D budget per faculty $(\log )$ & & $0.352^{* * * *}$
\end{tabular}

Southwest entry $(-1)$

Southwest entry (0)

$0.485^{* * *}$

Southwest entry (1)

$0.405^{* *}$

$(0.162)$

Southwest entry $(2+)$

$0.564^{* * *}$

$(0.175)$

\begin{tabular}{lccc}
\hline Pair Fixed Effects & Yes & Yes & Yes \\
Year Fixed Effects & Yes & Yes & Yes \\
Number of pairs & 819 & 816 & 819 \\
Number of observations & 14187 & 14147 & 14187 \\
\hline
\end{tabular}

Notes: Robust standard errors in parentheses ${ }^{*} p<0.1,{ }^{* *} p<0.05$, *** $p<0.01$. The dependent variable is the number of copublications between pairs of scientists. Southwest entry is an indicator variable that takes value 1 if Southwest has started operating a flight from airports close to the respective scientists. SW entry $(-1)$ is an indicator variable if the observation is in the year preceding SW entry. SW entry (0) SW entry (1) SW entry (2+) are defined analogously for the year of SW entry, the year after SW entry, and two years or more after SW entry, respectively. All specifications include individual-pair fixed effects and year fixed effects. Estimation by Poisson Quasi-Maximum Likelihood. 
Figure 1: Dynamics of the effect of Southwest entry

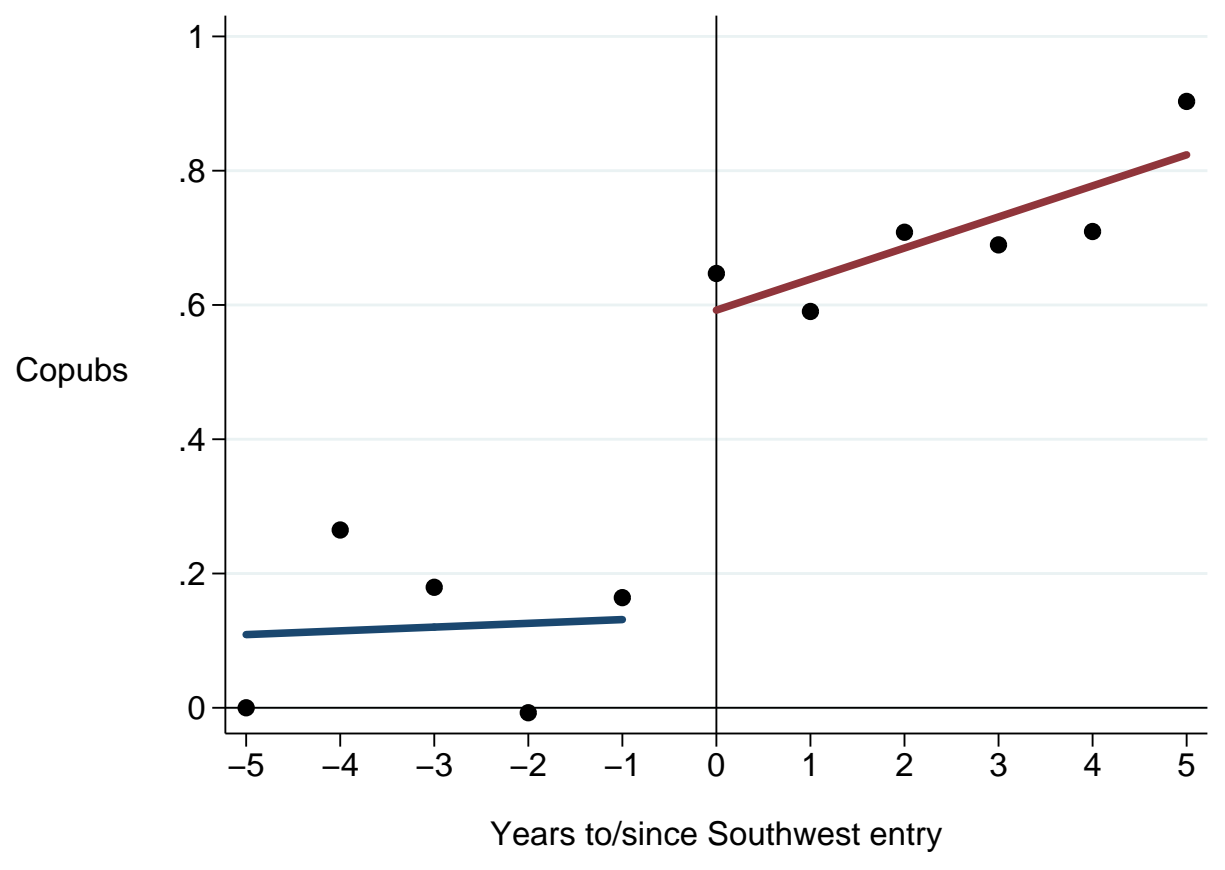

Notes: To generate this graph, we regress individual copublications on year fixed effects, pair effects and a set of indicator variables corresponding to 4 years before SW entry, 3 years before SW entry, ..., 4 years after SW entry, 5 years after SW entry (5 years before SW entry omitted). We then plot the coefficients associated with these indicator variables against time from/to Southwest entry, superimposing a linear fit line before entry and after entry.

Table 5: Effect of Southwest entry on cites-weighted co-publications, and other publications of the pair members

\begin{tabular}{lcccc}
\hline & $\begin{array}{c}(1) \\
\text { Copublications }\end{array}$ & $\begin{array}{c}(2) \\
\text { Copublications } \\
\text { cites-weighted) }\end{array}$ & $\begin{array}{c}(3) \\
\text { Other publications }\end{array}$ & $\begin{array}{c}\text { Other publications } \\
\text { (cites-weighted) }\end{array}$ \\
\hline Southwest entry & $0.482^{* * *}$ & $0.794^{* * *}$ & $0.110^{* * *}$ & $0.104^{* * *}$ \\
& $(0.118)$ & $(0.185)$ & $(0.019)$ & $(0.032)$ \\
\hline Pair Fixed Effects & Yes & Yes & Yes & Yes \\
Year Fixed Effects & Yes & Yes & Yes & Yes \\
Number of pairs & 819 & 798 & 819 & 819 \\
Number of obs. & 14187 & 13807 & 14187 & 14187 \\
\hline
\end{tabular}

Notes: Robust standard errors in parentheses ${ }^{*} p<0.1,{ }^{* *} p<0.05,{ }^{* * *} p<0.01$. Southwest entry is an indicator variable that takes value 1 if Southwest has started operating a flight from airports close to the respective scientists. Other publications is defined as the publications of the first pair members plus the publications of the second pair member minus twice the number of copublications between them. All specifications include individual-pair fixed effects and year fixed effects. Estimation by Poisson Quasi-Maximum Likelihood. 
Table 6: Effect of Southwest entry on co-publications - intensive and extensive margin

\begin{tabular}{lcccccccc}
\hline & \multicolumn{3}{c}{ Copublications } & & \multicolumn{3}{c}{ Cites-weighted copublications } \\
\cline { 2 - 3 } & $(1)$ & $(2)$ & $(3)$ & & $(4)$ & $(5)$ & $(6)$ \\
& All & Intensive & Extensive & & All & Intensive & Extensive \\
\hline Southwest entry & $0.482^{* * *}$ & $0.746^{* * *}$ & $0.390^{* * *}$ & & $0.794^{* * *}$ & 0.436 & $0.858^{* * *}$ \\
& $(0.118)$ & $(0.232)$ & $(0.131)$ & & $(0.185)$ & $(0.365)$ & $(0.194)$ \\
\hline Pair Fixed Effects & Yes & Yes & Yes & & Yes & Yes & Yes \\
Year Fixed Effects & Yes & Yes & Yes & & Yes & Yes & Yes \\
Number of pairs & 819 & 71 & & 748 & & 798 & 71 & 727 \\
Number of observations & 14187 & 1284 & 12903 & & 13807 & 1284 & 12523 \\
\hline
\end{tabular}

Notes: Robust standard errors in parentheses ${ }^{*} p<0.1,{ }^{* *} p<0.05$, ${ }^{* * *} p<0.01$. The dependent variable is the number of copublications between pairs of scientists (columns 1-3) or cites-weighted copublications (columns 4-6). Southwest entry is an indicator variable that takes value 1 if Southwest has started operating a flight from airports close to the respective scientists. Column 1 is the baseline specification. Column 2 and 5 restricts the sample to pairs of scientists who collaborate both before and after Southwest entry, while column 3 and restrict the sample to pairs of scientists who collaborate either before or after entry, but not both. All specifications include individual-pair fixed effects and year fixed effects. Estimation by Poisson Quasi-Maximum Likelihood. 


\section{Table 7: Effect of Southwest entry on co-publications - heterogeneous effects}

\begin{tabular}{|c|c|c|c|c|c|c|}
\hline $\mathrm{DV}=$ Co-publications & $(1)$ & $(2)$ & $(3)$ & $(4)$ & $(5)$ & $(6)$ \\
\hline Southwest entry & $\begin{array}{c}0.268^{* *} \\
(0.124)\end{array}$ & $\begin{array}{c}0.108 \\
(0.160)\end{array}$ & $\begin{array}{c}0.279 * * \\
(0.138)\end{array}$ & $\begin{array}{c}0.348^{* * *} \\
(0.127)\end{array}$ & $\begin{array}{c}0.264 \\
(0.166)\end{array}$ & $\begin{array}{c}-0.487^{* *} \\
(0.247)\end{array}$ \\
\hline $\begin{array}{l}\text { Southwest X both below } 50 \\
\text { (at time of entry) }\end{array}$ & $\begin{array}{l}0.668^{* *} \\
(0.271)\end{array}$ & & & & & $\begin{array}{c}0.578^{* * *} \\
(0.219)\end{array}$ \\
\hline $\begin{array}{l}\text { Southwest } \mathrm{X} \text { one more } \\
\text { productive than dept average }\end{array}$ & & $\begin{array}{l}0.294^{*} \\
(0.179)\end{array}$ & & & & $\begin{array}{l}0.302^{*} \\
(0.169)\end{array}$ \\
\hline $\begin{array}{l}\text { Southwest } \mathrm{X} \text { both more } \\
\text { productive than dept average }\end{array}$ & & $\begin{array}{c}0.725^{* * *} \\
(0.231)\end{array}$ & & & & $\begin{array}{c}0.751^{* * *} \\
(0.217)\end{array}$ \\
\hline $\begin{array}{l}\text { Southwest X different } \\
\text { type of chemistry }\end{array}$ & & & $\begin{array}{l}0.471^{* *} \\
(0.222)\end{array}$ & & & $\begin{array}{l}0.300^{*} \\
(0.174)\end{array}$ \\
\hline $\begin{array}{l}\text { Southwest X both in dept. } \\
\text { with below median R\&D budget }\end{array}$ & & & & $\begin{array}{c}0.377 \\
(0.251)\end{array}$ & & $\begin{array}{l}0.228 \\
(0.194)\end{array}$ \\
\hline $\begin{array}{l}\text { Southwest X distance } \\
\text { between } 500 \text { and } 2000 \text { miles }\end{array}$ & & & & & $\begin{array}{c}0.229 \\
(0.229)\end{array}$ & $\begin{array}{c}0.250 \\
(0.219)\end{array}$ \\
\hline $\begin{array}{l}\text { Southwest X distance } \\
\text { above } 2000 \text { miles }\end{array}$ & & & & & $\begin{array}{c}0.512 \\
(0.314)\end{array}$ & $\begin{array}{c}0.344 \\
(0.230)\end{array}$ \\
\hline Pair Fixed Effects & Yes & Yes & Yes & Yes & Yes & Yes \\
\hline Year Fixed Effects & Yes & Yes & Yes & Yes & Yes & Yes \\
\hline Number of pairs & 819 & 819 & 819 & 819 & 819 & 819 \\
\hline Number of observations & 14187 & 14187 & 14187 & 14187 & 14187 & 14187 \\
\hline
\end{tabular}

Notes: Robust standard errors in parentheses ${ }^{*} p<0.1,{ }^{* *} p<0.05,{ }^{* * *} p<0.01$. Southwest entry is an indicator variable that takes value 1 if Southwest has started operating a flight from airports close to the respective scientists. All specifications include individual-pair fixed effects and year fixed effects. Estimation by Poisson Quasi-Maximum Likelihood. 


\section{Appendix}

Table A1: Effect of Southwest entry on co-publications - Alternative functional forms

\begin{tabular}{lccc}
\hline & $\begin{array}{c}(1) \\
\text { Poisson } \\
\text { Copublications }\end{array}$ & $\begin{array}{c}(2) \\
\text { OLS }\end{array}$ & $\begin{array}{c}(3) \\
\text { OLS }\end{array}$ \\
\hline Copublications & Any copublication \\
\hline Pair Fixed Effects & Yes & $0.049^{* * *}$ & $0.027^{* * *}$ \\
Year Fixed Effects & Yes & Yes & $(0.010)$ \\
Number of pairs & 819 & Yes & Yes \\
Number of obs. & 14187 & 14187 & Yes \\
\hline
\end{tabular}

Notes: Robust standard errors in parentheses ${ }^{*} p<0.1,{ }^{* *} p<0.05,{ }^{* * *} p<0.01$. Southwest entry is an indicator variable that takes value 1 if Southwest has started operating a flight from airports close to the respective scientists. Column 1 is the baseline regression at the individual pair level (estimated by Poisson Quasi-Maximum Likelihood.) Column 2 estimates the same specification with ordinary least squares. Column 3 is a linear probability model with an indicator variable for any copublication.

Table A2: Stability of results across different subfields of chemistry

\begin{tabular}{lccccc}
\hline DV=copublications & $\begin{array}{c}(1) \\
\text { Physical } \\
\text { chemistry }\end{array}$ & $\begin{array}{c}(2) \\
\text { Biochemistry }\end{array}$ & $\begin{array}{c}(3) \\
\text { Inorganic } \\
\text { chemistry }\end{array}$ & $\begin{array}{c}(4) \\
\text { Material } \\
\text { Science }\end{array}$ & $\begin{array}{c}(5) \\
\text { Organic } \\
\text { Chemistry }\end{array}$ \\
\hline Southwest entry & $0.496^{* * *}$ & $0.387^{*}$ & $0.477^{* *}$ & $0.527^{* *}$ & $0.646^{* * *}$ \\
& $(0.180)$ & $(0.206)$ & $(0.243)$ & $(0.233)$ & $(0.247)$ \\
\hline Pair Fixed Effects & Yes & Yes & Yes & Yes & Yes \\
Year Fixed Effects & Yes & Yes & Yes & Yes & Yes \\
Nr of pairs & 392 & 217 & 166 & 133 & 175 \\
Nr of observations & 7010 & 3587 & 2922 & 2252 & 3066 \\
\hline
\end{tabular}

Notes: Robust standard errors in parentheses ${ }^{*} p<0.1,{ }^{* *} p<0.05,{ }^{* * *} p<0.01$. Southwest entry is an indicator variable that takes value 1 if Southwest has started operating a flight from airports close to the respective scientists. Estimation by Poisson Quasi-Maximum Likelihood. 
Table A3: Using journals to define field of specialization

\begin{tabular}{ll}
\hline Field & Journal (examples) \\
\hline Biochemistry & Journal of Biological Chemistry, Biochemistry \\
Inorganic Chemistry & Inorganic Chemistry \\
Material Science & Macromolecules, Advanced Materials \\
Physical Chemistry & Journal of Physical Chemistry \\
Organic Chemistry & Journal of Organic Chemistry, Organic Letters \\
\hline \hline
\end{tabular}

The area of specialization for a given faculty member is inferred from the journals $\mathrm{s} /$ he publishes in. For instance, a faculty member who publishes often in the Journal of Biological Chemistry is assumed to be specialized in biochemistry. 